\title{
Fabrication of Ultralow Ice-Adhesion Slippery Liquid Infused Porous Surfaces on Aluminum Alloy (7075-T651)
}

\author{
Yuan Yuan ${ }^{1, *}$, Liang Wang ${ }^{1}$, Guoyong Liu ${ }^{2}$ and Ruijin Liao ${ }^{2}$ \\ 1 College of Materials Science and Engineering, Chongqing University, Chongqing 400044, China; \\ liangwang@cqu.edu.cn \\ 2 State Key Laboratory of Power Transmission Equipment \& System Security and New Technology, \\ Chongqing University, Chongqing 400044, China; GuoyongLiu@cqu.edu.cn (G.L.); rjliao@cqu.edu.cn (R.L.) \\ * Correspondence: yuany@cqu.edu.cn
}

Received: 31 August 2020; Accepted: 22 October 2020; Published: 24 October 2020

\begin{abstract}
Slippery liquid infused porous surfaces (SLIPS) have been considered to be potential and effective method for anti-icing. Much work needed to be done for the application in field. In this study, SLIPS were successfully fabricated on 7075-T651 aluminum alloy by anodizing in phosphoric acid solution with three different voltage parameters and coating lubricant. Then the most suitable anodization parameters of samples were selected through the anti-icing performance tests. The best as-prepared surface exhibited ultralow ice-adhesion strength, which reduced from 261 to $6 \mathrm{kPa}$. Meanwhile, the freezing time of water-drop on aluminum alloy surfaces have been dramatically delayed at -5 and $-10{ }^{\circ} \mathrm{C}$ (humidity of $75 \% \pm 5 \%$ ), respectively. Moreover, the durability of the SLIPS have also been investigated. Cycles of icing/deicing, mechanical damage, thermal and UV exposure were used to investigate the durability of SLIPS, and SLIPS could still show low ice-adhesion strength.
\end{abstract}

Keywords: ice-adhesion; anti-icing; aluminum alloy; anodization; durability

\section{Introduction}

Ice accretion might lead to serious harm to outdoor facilities, such as ships, wind turbines, power transmission, especially the wings, fuselage and engine of aircrafts [1-4]. Over the past decade, the icing problems in field have been taken seriously both by academics and industrial researchers. Much work has been done to improve the anti-icing property of various surfaces. Unfortunately, the anti-icing for the aluminum alloy, which was widely used, has not been paid enough attention in the present situation. Aluminum alloy (7075-T651) was typically used for the manufacturing of aircraft components because of its good corrosion resistance, mechanical properties and anode reaction $[5,6]$. Aircraft icing might lead to flight accidents due to the damage of aerodynamic shape, such as ice was formed at the wing leading edge. Additionally, ice formation on the surface of aircraft has been a burning problem for years $[7,8]$. Therefore, it was necessary to develop surfaces with low ice-adhesion strength so that ice could fall off from the surfaces easily.

In recent years, the superhydrophobic surfaces (contact angle (CA) $>150^{\circ}$ and contact angle hysteresis $(\mathrm{CAH})<10^{\circ}$ ) have gradually considered to be a potential and reliable approach for the icing problem $[9,10]$. However, superhydrophobicity did not mean anti-icing property [11]. When most superhydrophobic surfaces exposed into low temperature and high humidity for a certain period of time, the droplets of water vapor, suspended in air, would get into the micro/nanostructure of the surfaces, then freeze, which would lead to much severer icing [12,13]. Moreover, the durability of the superhydrophobic surfaces were another significant problem for application. Superhydrophobic 
surfaces were easily destroyed by external forces and icing/deicing cycles. Therefore, more effective and durable anti-icing surfaces should be developed.

To obtain more reliable surfaces, a new kind of surfaces named slippery liquid infused porous surfaces (SLIPS) were proposed. Slippery liquid infused porous surfaces were porous nanostructures impregnated with a low surface tension lubricant, which were inspired by the Nepenthes pitchers plants and reported by Wong et al. [14]. Various methods have been used to prepare the SLIPS, which meant SLIPS might be suitable for anti-icing [15-17]. Furthermore, SLIPS also exhibited self-cleaning, self-healing and repel water and other liquids [18-20], which provided possibility of practical applications.

Ice-adhesion strength was a certain key factor for anti-icing performance, which could lead the falling of ice. In addition, the durability of SLIPS should also be considered as an important vital factor for practical applications. In this study, we prepared suitable porous surfaces by optimizing the anodizing parameters and the surfaces were modified by silane and lubricating oil. SLIPS with ultralow ice-adhesion strength were successfully fabricated on the surface of 7075-T651 aluminum alloy. SLIPS could still exhibit ultralow ice-adhesion strength after frosting on the surfaces, which meant frosting would not make anti-ice failure. The anti-icing performance of as-prepared surfaces have been studied in low temperature. Besides, the durability of SLIPS have also been investigated.

\section{Materials and Methods}

\subsection{Materials}

$20 \mathrm{~mm} \times 20 \mathrm{~mm} \times 1.5 \mathrm{~mm}$ aluminum alloy plates (7075, Al-Zn-Mg-Cu), emery paper No.1000, ethanol (99.7 wt \%, Chongqing Chuandong Chemical Co., Ltd., Chongqing, China), Dupont Krytox GPL 100, $\mathrm{H}_{3} \mathrm{PO}_{4}$ (85.0 wt \%, Chongqing Chuandong Chemical Co., Ltd., Chongqing, China), hexadecyltrimethoxy silane ( $2 \mathrm{wt} \%$, Aladdin, Shanghai, China) were used in this study.

\subsection{Surface Preparation}

To prepare the SLIPS, the aluminum alloy plates were cut into $20 \mathrm{~mm} \times 20 \mathrm{~mm} \times 1.5 \mathrm{~mm}$ small pieces and washed with deionized water (DI), followed by ultrasonically cleaned in ethanol for $10 \mathrm{~min}$ to remove grease and contaminants. The aluminum alloy plate worked as anode and stainless steel plate was used as cathode in anodization process, which was carried out in $0.3 \mathrm{~mol} / \mathrm{L}$ phosphoric acid at voltage of $110,120,130 \mathrm{~V}$ and temperature range of $20-25{ }^{\circ} \mathrm{C}$ for $10 \mathrm{~min}$ to obtain three different porous surfaces. Then, the samples were rinsed out with deionized water and dried for $5 \mathrm{~min}$. The surfaces were modified with $2 \mathrm{wt} \%$ hexadecyltrimethoxy silane solution (prepared by ethanol and hexadecyltrimethoxy silane) for $30 \mathrm{~min}$ to decrease surface energy and dried for $10 \mathrm{~min}$. At last, the SLIPS were fabricated after immersing in perfluorated lubricant Dupont Krytox GPL 100 for $2 \mathrm{~h}$. Three different SLIPS samples were named SLIPS1, SLIPS2 and SLIPS3, which anodizing voltages were 110,120 and $130 \mathrm{~V}$, respectively.

\subsection{Characterization}

SLIPS morphologies were analyzed through field emission scanning electron microscope (JSM-7800F and FEI Nova 400 FEG-SEM, JEOL, Tokyo, Japan). The wettability of the samples were evaluated through a contact angle (CA) meter (Drop meter A-100, manufacturer, Shanghai, China). A measure of $10 \mu \mathrm{L}$ water droplet was dropped on the surfaces of the samples and the CA images were recorded by a camera.

The chemical composition of surfaces were characterized with Fourier Transform Infrared (FTIR, Bruker, Karlsruhe, German) and X-ray photoelectron spectroscopic (XPS, ESCALAB250Xi, Thermo Fisher, Waltham, MA, USA). SLIPS2 was selected as a typical sample and compared with the bare sample.

The ice adhesion test platform was made by a semiconductor refrigerator, a high precision temperature controller (temperature control range: $-25-80^{\circ} \mathrm{C}$, control accuracy: $\pm 0.1^{\circ} \mathrm{C}$ ), an $\mathrm{XY}$ 
motion stage, a force transducer (HP-200, Handpi, Shenzhen, China) and a plastic cylinder (inner diameter $=14 \mathrm{~mm}$ ) filled with DI-water $(1 \mathrm{~mL})$. Here, all ice adhesion strength tests were carried out at $-20{ }^{\circ} \mathrm{C}$ and icing for $90 \mathrm{~min}$. Then $\mathrm{XY}$ motion stage was moved slowly until the cylinder shifted on the surface and we recorded the value of force transducer at this moment.

In mechanical stability study, we used emery paper NO.1000 as an abrasion media with applied weight of $100 \mathrm{~g}$ moved $5 \mathrm{~cm}$ on the sample surface for 15 times. The thermal stability of SLIPS was tested by drier at $75^{\circ} \mathrm{C}$ for 7 days. The weathering resistance was tested by a UV/Condensation weathering instrument (Dongguan Kowin Testing Equipment Co., Ltd., Dongguan, China). According to ASTM G154-12a, we exposed the samples to UV light $\left(0.77 \mathrm{~W} / \mathrm{m}^{2}\right)$ for $4 \mathrm{~h}$, water spray and condensation for $4 \mathrm{~h}$ as a cycle. The whole process lasted for 7 days.

\section{Results and Discussion}

\subsection{Morphology of Surface and Wettability}

Figure 1a-h showed the micromorphology of the bare aluminum alloy surface, SLIPS1, SLIPS2 and SLIPS3 at different magnification. And the CA of different samples also exhibited in Figure 1a,c,e,g. The bare aluminum surface was relatively smooth, as shown in Figure 1a,b. Additionally, the morphology of SLIPS1, SLIPS2 and SLIPS3 shown in Figure 1c-h illustrated the formation of micro-nanostructured porous on aluminum alloy surface. As shown in Figure 1d,h, there were many rough structures on the surfaces of SLIPS1 and SLIPS3. The surface morphology of SLIPS2 was smoother than SLIPS1 and SLIPS3 as shown in Figure 1f. We selected 200 holes in different areas of each sample surface. After measurement and statistics, the average pore size of SLIPS1, SLIPS2 and SLIPS3 were about 120, 150 and $100 \mathrm{~nm}$, respectively. And the results of repeated experiments showed that the morphology of porous surface prepared by different anodic oxidation voltage was also different.

Besides, we measured CA of bare surface, SLIPS1, SLIPS2 and SLIPS3 by contact angle meter. As the results showed in Figure 1a,c,e,g, the highest CA was $100^{\circ}$, which belonged to SLIPS2. Compared with the CA of bare sample, SLIPS1 and SLIPS3 also exhibited higher CA.

\subsection{Chemical Composition of Surface}

The FTIR and XPS results of bare sample surface and SLIPS2 were exhibited in Figures 2 and 3, respectively. Compared with the spectrum of bare sample, three more peaks of SLIPS2 were showed in Figure 2. For SLIPS2, the absorption peak at 1226 and $1180 \mathrm{~cm}^{-1}$ related to the stretching vibrations of $-\mathrm{CF}_{2}$ and $-\mathrm{CF}_{3}$, respectively [21]. The absorption peak at $1117 \mathrm{~cm}^{-1}$ was assigned to the stretching vibrations of $\mathrm{Si}-\mathrm{O}$, while the peak at $979 \mathrm{~cm}^{-1}$ was associated with the stretching vibrations of $\mathrm{C}-\mathrm{O}-\mathrm{C}$ [22]. Figure 3 showed the $\mathrm{X}$-ray photoelectron spectra of bare sample surface and SLIPS2. The XPS revealed $\mathrm{Al}(2 p)$ peak at $74.8 \mathrm{eV}, \mathrm{Al}(2 s)$ peak at $119.3 \mathrm{eV}, \mathrm{C}(1 s)$ peak at $284.2 \mathrm{eV}$, and $\mathrm{O}(1 s)$ peak at $531.7 \mathrm{eV}$. After modification, the XPS of SLIPS2 exhibited two more peaks of $\mathrm{F}(1 \mathrm{~s})$ at $688.4 \mathrm{eV}$ and $\mathrm{Si}(2 p)$ at $102 \mathrm{eV}$ beside all the peaks appearing in aforementioned XPS results [23]. The FTIR and XPS results confirm the modification of silane and lubricant. 

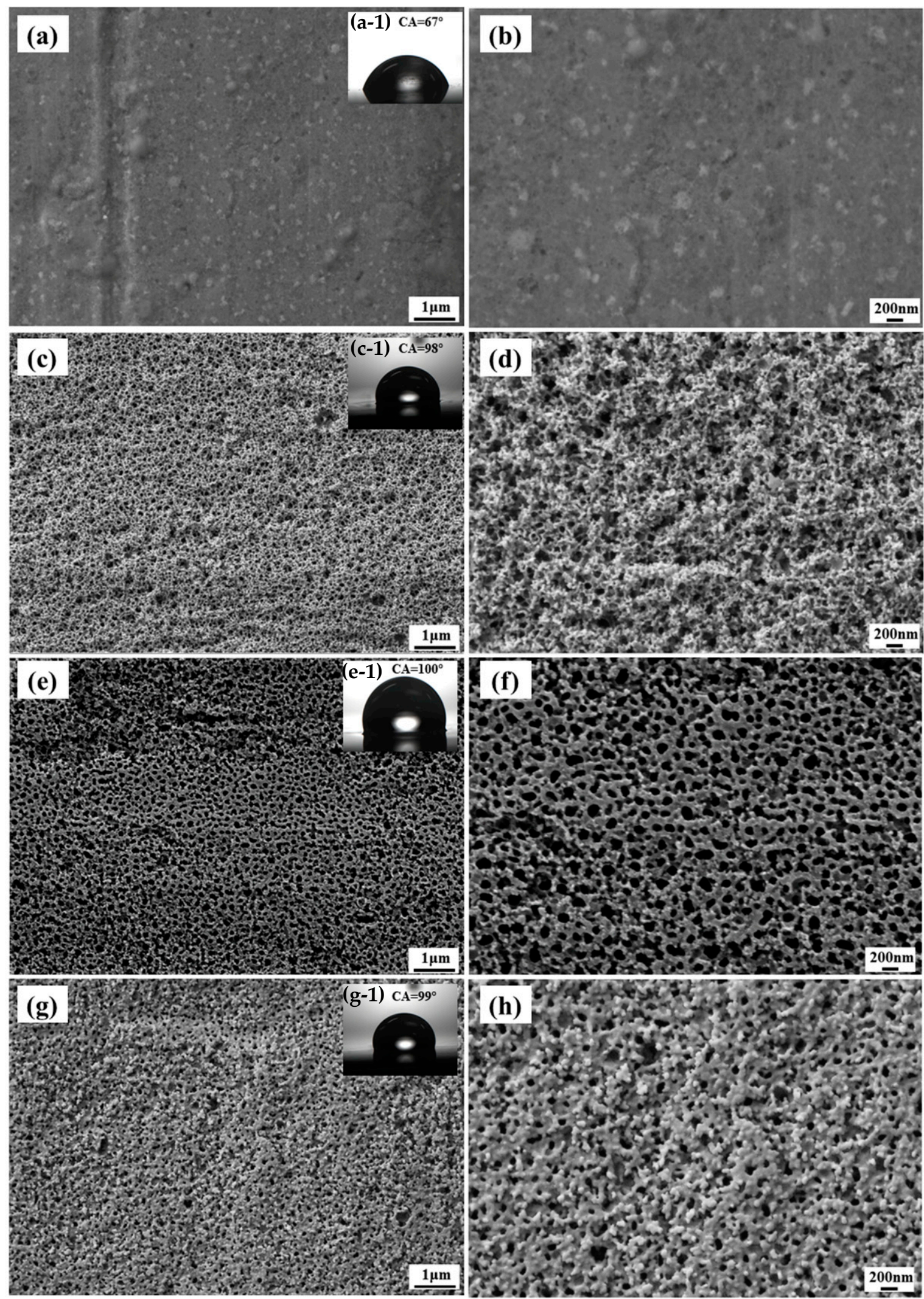

Figure 1. (a,b) The micromorphology of bare surface, $(\mathbf{c}, \mathbf{d})$ the micromorphology of SLIPS1, $(\mathbf{e}, \mathbf{f})$ the micromorphology of SLIPS2, $(\mathbf{g}, \mathbf{h})$ the micromorphology of SLIPS3; (a-1,c-1,e-1,g-1) exhibited CA of bare surface, SLIPS1, SLIPS2 and SLIPS3, respectively. SLIPS, slippery liquid infused porous surfaces. 


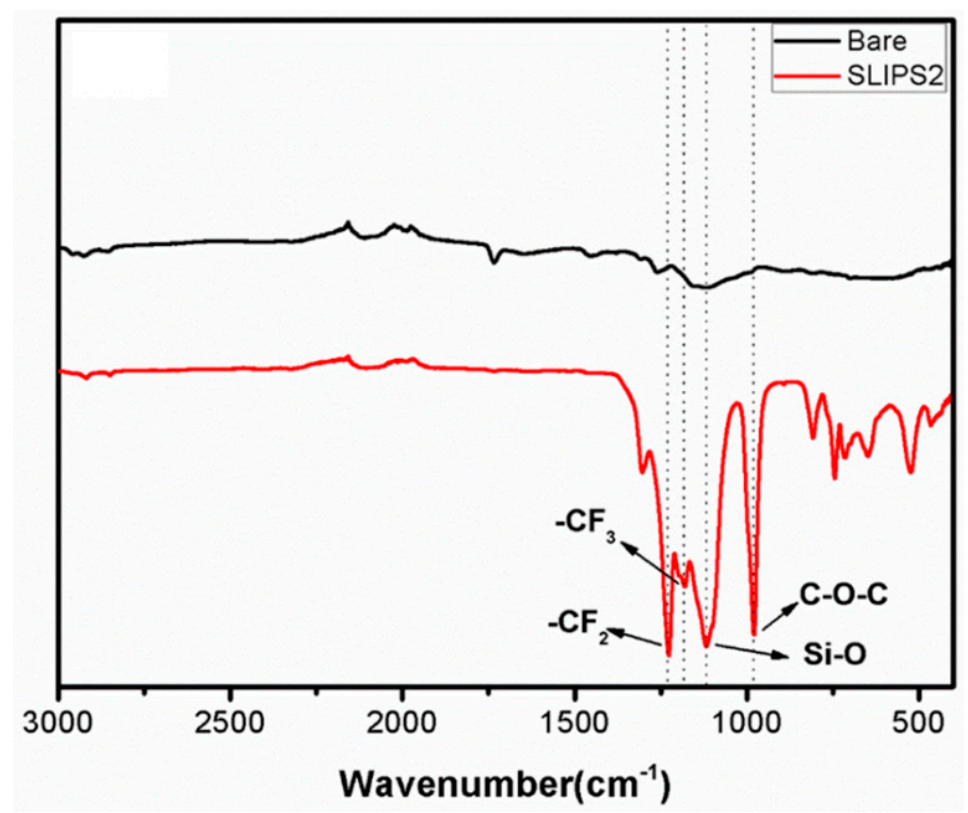

Figure 2. The FTIR spectrum of bare sample and SLIPS2.

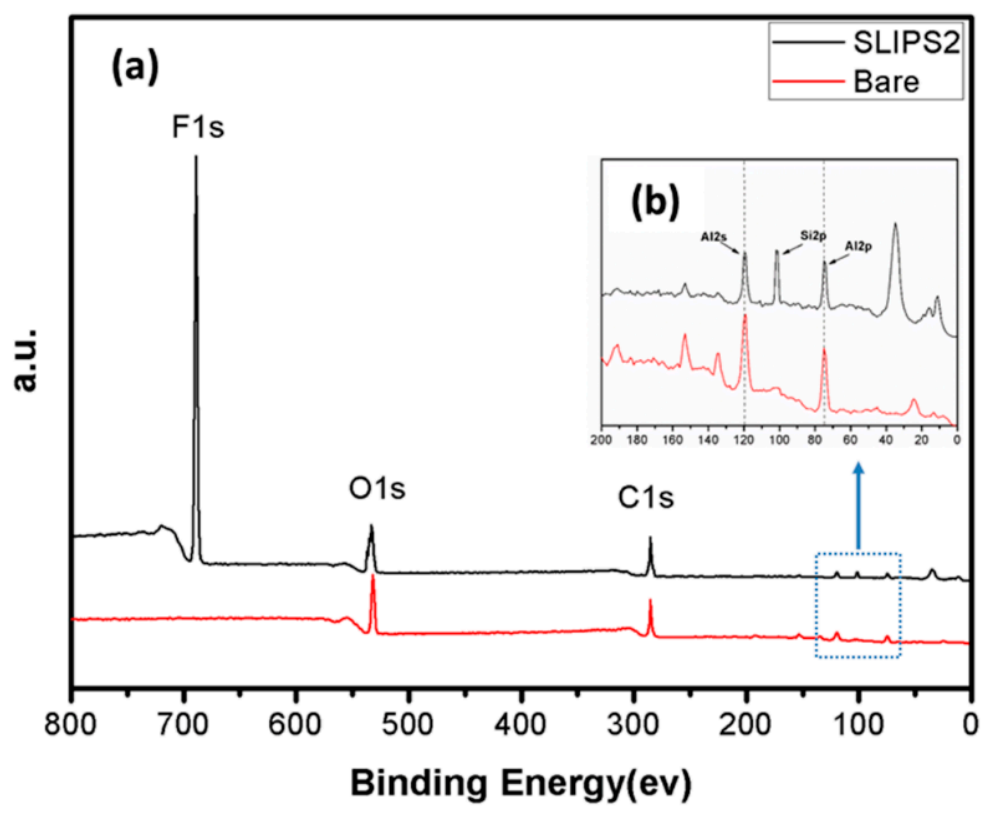

Figure 3. The XPS spectrum of bare sample and SLIPS2: (a) 0-800 eV; (b) 0-200 eV.

\subsection{Anti-Icing Performance}

\subsubsection{Ice Adhesion Strength}

Ice adhesion strength was an important part of the test of anti-icing performance. It provided an indication of how easy the formed ice can be removed from the surface. Some researchers suggested that ice-adhesion strength of icephobic surfaces should not exceed 0.1 MPa [24]. Here, we compared ice-adhesion strength of three different samples with bare sample. All samples were fixed on a semiconductor refrigerator at $-20^{\circ} \mathrm{C}$ and icing for $90 \mathrm{~min}$. Figure 4 shows the shear ice adhesion strength results of bare sample, SLIPS1, SLIPS2 and SLIPS3, which were 261, 12, 6 and $23 \mathrm{kPa}$, respectively. Obviously, SLIPS2 exhibited ultralow ice adhesion strength and we thought that the prepared surface showed good lubricity and effectively reduced the adhesion of ice on the sample 
surface. Therefore, $120 \mathrm{~V}$ anodizing voltage was regarded as a more appropriate parameter for fabricating porous surface. SLIPS2 would be used as a typical sample for subsequent experiments.

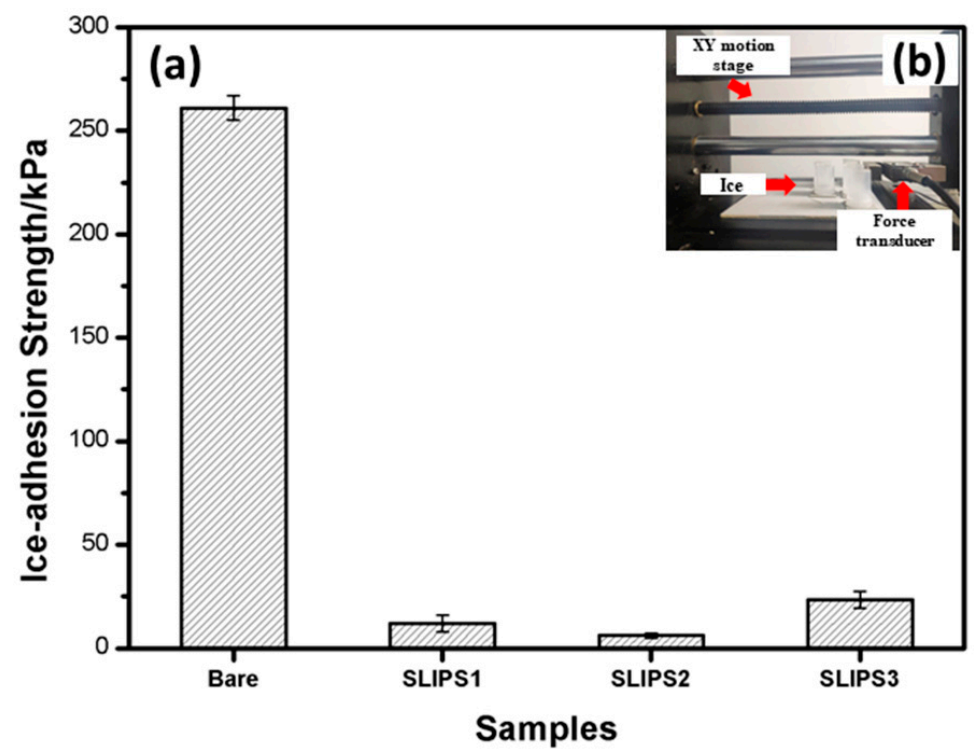

Figure 4. (a) Ice-adhesion strength of bare sample, SLIPS1, SLIPS2 and SLIPS3, which were tested at $-20^{\circ} \mathrm{C}$. This inset $(\mathbf{b})$ showed the ice adhesion test platform.

\subsubsection{Anti-Icing Performance after Frosting}

Frosting was a common phenomenon under the condition of low temperature and high humidity. Some reports indicated that superhydrophobic surfaces would lose efficacy because of frosting, while SLIPS would be an alternative to superhydrophobic surfaces [25]. Frost nucleation occurs on all areas of the superhydrophobic surface, including post tops, sidewalls, and valleys of the surface texture without any particular preference, leading to the loss of superhydrophobic properties, which made icing more serious [12]. On the contrary, the lubricant filled the microstructure of SLIPS and formed a very thin lubrication layer on the surface, which prevented the frosting process. However, there were few studies to prove it. Therefore, we designed an experiment to test anti-icing performance of SLIPS2 after frosting, as shown in Figure 5. Firstly, bare sample and SLIPS2 were frosted on semiconductor refrigerator for $30 \mathrm{~min}$ at $-10{ }^{\circ} \mathrm{C}$ and humidity of $85 \%$. Then, both of them iced for $90 \mathrm{~min}$ at $-20^{\circ} \mathrm{C}$ and tested the ice adhesion strength. The results were shown in Figure 5, SLIPS2 could still exhibit ultralow ice adhesion strength, which was $8 \mathrm{kPa}$. Actually, porous surfaces of SLIPS were completely filled with lubricant, the droplets of water vapor could only accumulate on the surface of lubricant. Consequently, frosting had no effect on the anti-icing performance of SLIPS.

\subsubsection{Icing Delay Time}

A long icing delay time could reduce the probability of ice formation or provide sufficient time for water droplets to leave the sample surface before ice formation. We dropped five water drops on different position of each sample surface, and the freezing time of each droplet $(10 \mu \mathrm{L})$ was observed and counted at -5 and $-10{ }^{\circ} \mathrm{C}$ (humidity of $75 \% \pm 5 \%$ ), respectively. The whole process was repeated 20 times, and the freezing time of 100 water drops was counted for each sample. Figure $6 a, b$ showed the number of freezing drops on different sample surfaces in each time period at -5 and $-10{ }^{\circ} \mathrm{C}$ (humidity of $75 \% \pm 5 \%$ ), respectively. Compared with bare aluminum alloy, SLIPS1, SLIPS2 and SLIPS3 were endowed with a longer icing delay time, especially for SLIPS2. Icing delay time was closely related to thermal transmission at the contact interface [26], and ice nucleation [27,28]. On the one hand, SLIPS samples have a relatively high CA and less contact area reduced thermal transmission. On the other hand, because of the infused low surface energy lubricant that posed a higher free energy 
barrier, SLIPS were considered a promising candidate to inhibit ice nucleation. In addition, according to the results of ice adhesion strength and icing delay time, SLIPS2 would be used as a typical sample for subsequent experiments. Further, $120 \mathrm{~V}$ anodizing voltage was regarded as a more appropriate parameter for fabricating porous surfaces.

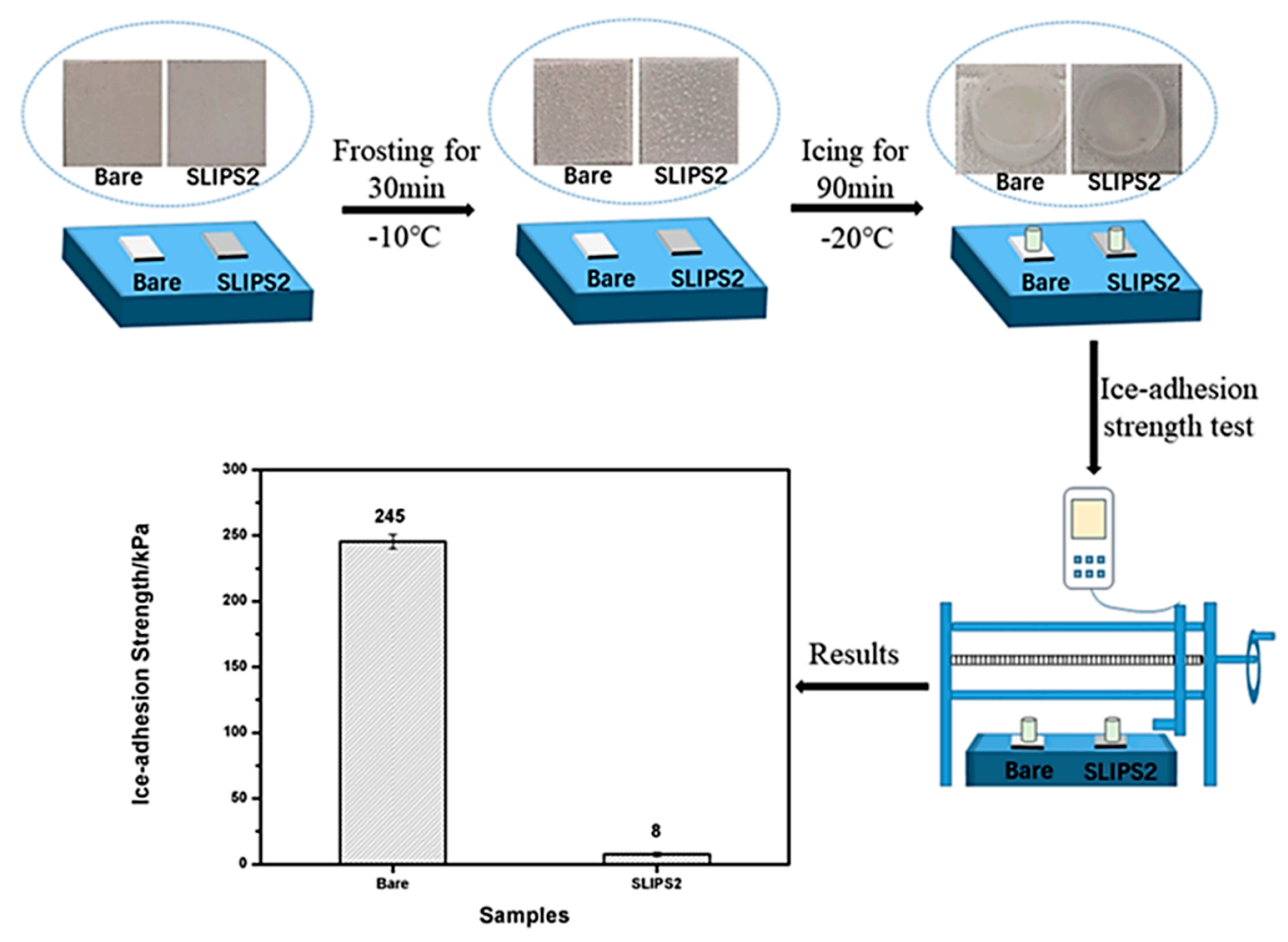

Figure 5. The process diagram of anti-icing performance test of SLIPS2 after frosting and results.
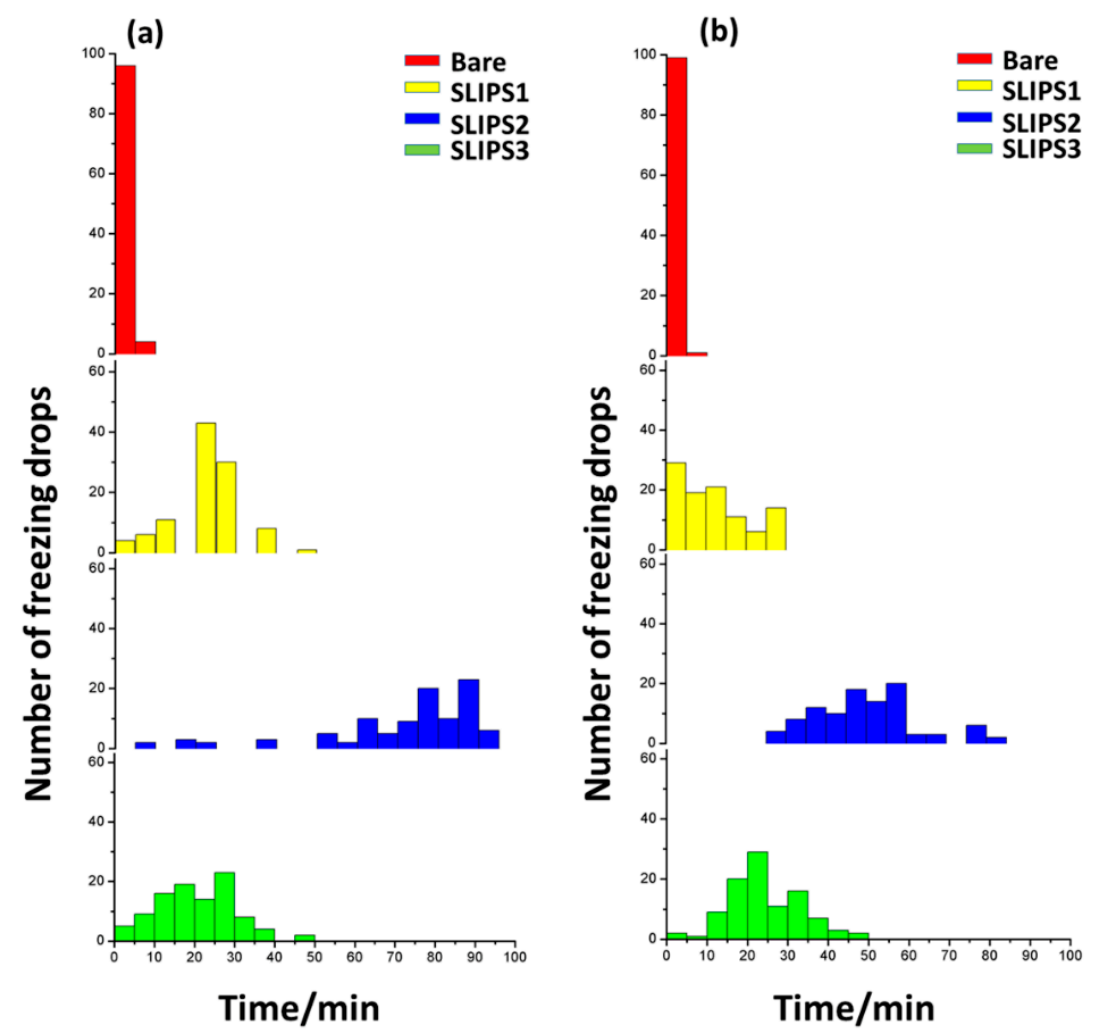

Figure 6. The number of freezing drops on bare samples, SLIPS1, SLIPS2 and SLIPS3 in each time period at $-5{ }^{\circ} \mathrm{C}(\mathbf{a})$ and $-10{ }^{\circ} \mathrm{C}(\mathbf{b})$. 


\subsection{Durability of SLIPS}

Actually, the durability of SLIPS was crucial for practical application. The lubricant of surface was easily depleted because of the external environment effect. We carried out 50 times icing/deicing cycles to test the durability of SLIPS2 and observed the changes of ice-adhesion strength. The results showed SLIPS2 ice adhesion strength had a slightly increase, but they still could maintain low ice adhesion strength $(50 \mathrm{kPa})$, which compared with bare sample and as shown in Figure 7 . After 50 times icing/deicing cycles, we thought SLIPS2 could compensate the loss of lubricant because of capillary action. Therefore, SLIPS2 exhibited a certain durability after icing/deicing cycles.

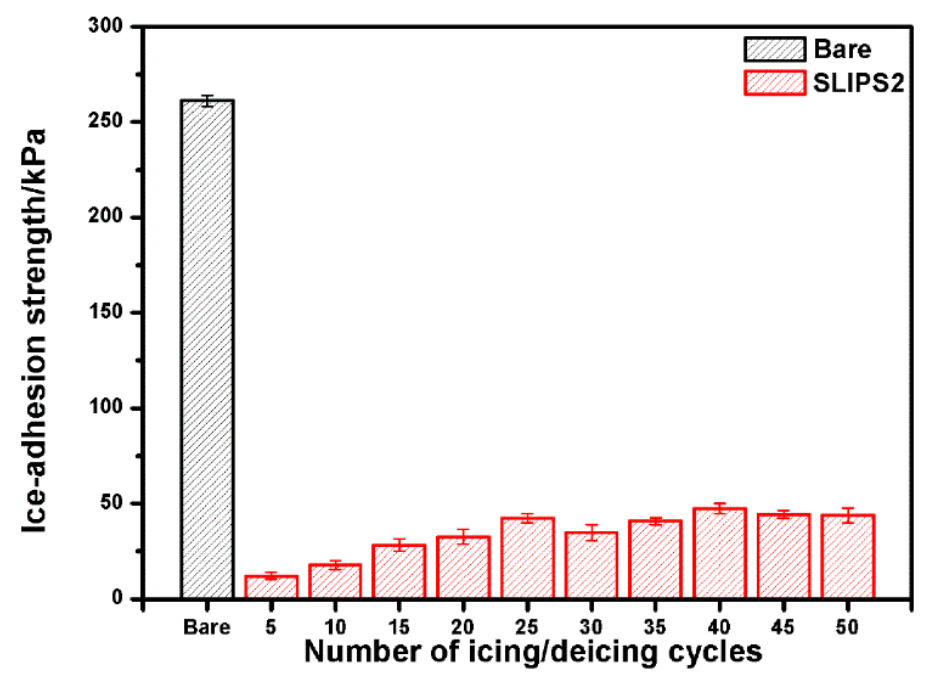

Figure 7. Variation of ice-adhesion strength of SLIPS2 after a number of icing/deicing cycles.

It was well known that the stability against mechanical was an important consideration for practical application of anti-icing surfaces. Figure 8 showed the results of mechanical durability of SLIPS2, under the shear abrasion of emery paper loaded with $100 \mathrm{~g}$ of force and 10 pieces of SLIPS2 were prepared to repeat this experiment. After abrasing for 15 times, SLIPS2 still maintained a lubricated surface with low ice-adhesion $(41 \mathrm{kPa})$. Actually, the micro-nanostructured film prepared by anodization had a good mechanical property, especially coated with lubricant. The lubricating layer could reduce friction coefficient of contact interface. Furthermore, the lubricant in the nanoporous film would migrate towards sample surface to heal the damage because of capillary forces.

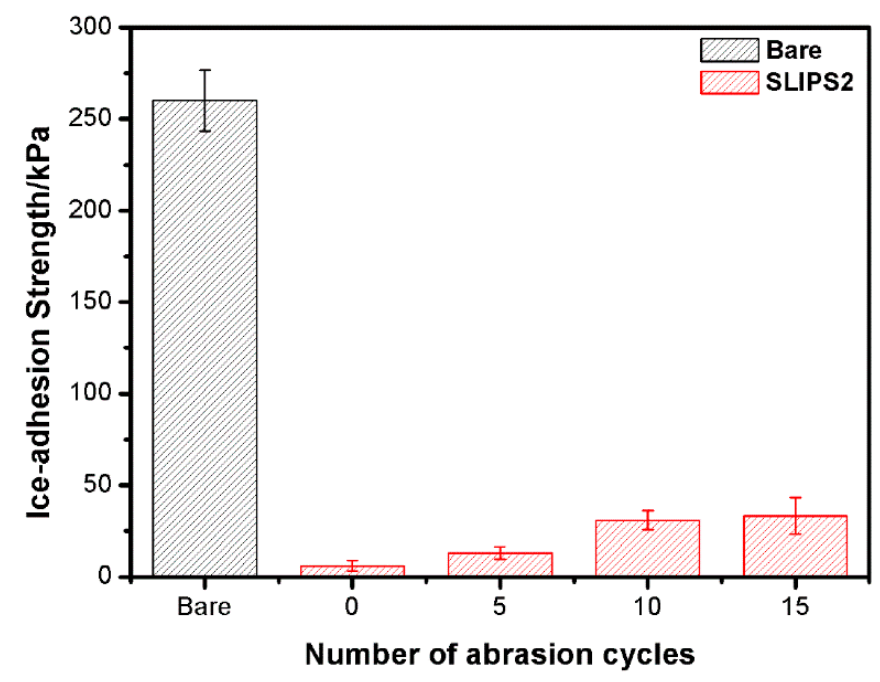

Figure 8. Variation of ice-adhesion strength of SLIPS2 after a number of abrasion cycles. 
Stable performance against heat and UV light was another important consideration for SLIPS practical applications in outdoor environment. Here we carried out the thermal stability test at $70{ }^{\circ} \mathrm{C}$ and weathering resistance test for 7 days, respectively. And the whole process repeated 10 times. As shown in Figure 9a,b, ice-adhesion strength of SLIPS2 increased drastically but still displayed a low value, which demonstrated the lubricating layer in our study came through the trails of thermal and UV light. This was because the lubricating layer on the porous surface was a stable material, and there was a strong interlock between the lubricant and the hole, thus reducing the consumption of lubricant.
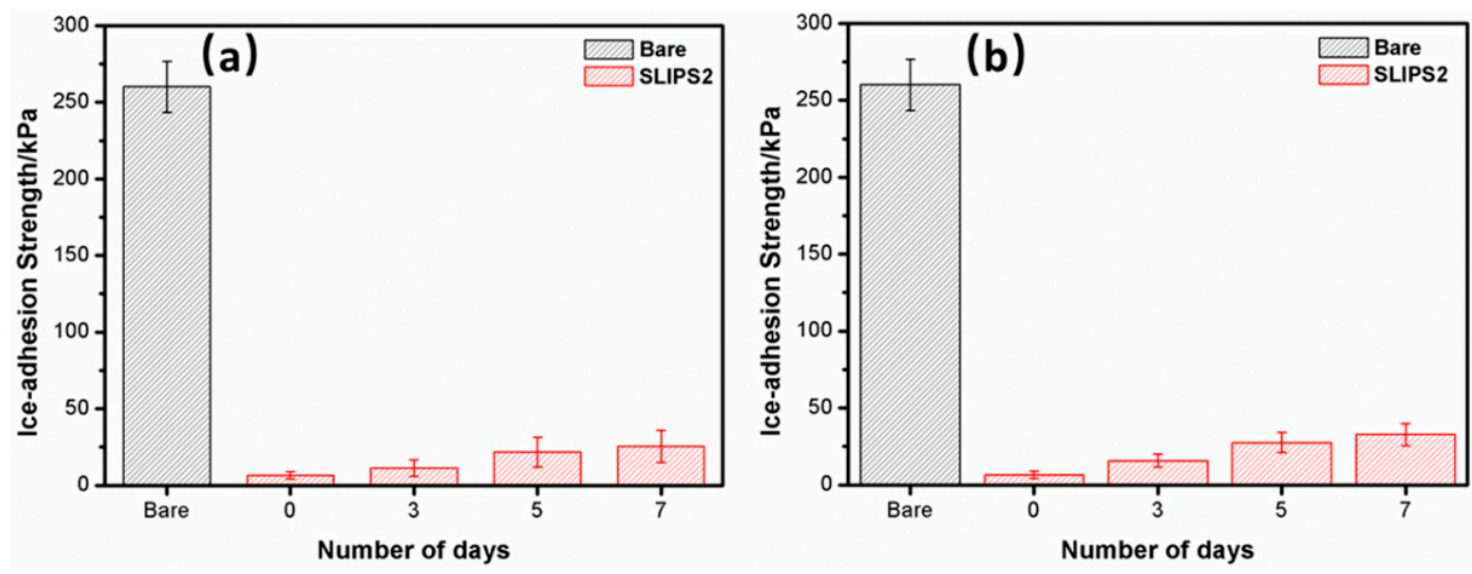

Figure 9. (a) variation of ice-adhesion strength of SLIPS2 under thermal condition at $75^{\circ} \mathrm{C}$ for 7 days; (b) variation of ice-adhesion strength of SLIPS2 under UV light exposure for 7 days.

\section{Conclusions}

In this study, we prepared porous structure on the surface of the aluminum alloy substrate (7075-T651) and modified by silane and lubricant. In addition, SLIPS with excellent anti-icing performance was fabricated by optimizing the anodizing voltage parameters $(120 \mathrm{~V})$. The as-prepared slippery surface showed excellent anti-icing performance including ultralow ice-adhesions strength, long icing delay time and we verified that it would not fail after frosting. In addition, we investigated the durability of SLIPS for the possibility of practical outdoor application. The results showed SLIPS could still exhibit low ice-adhesion strength after 50 cycles of icing/deicing, mechanical damage, thermal and UV exposure.

Author Contributions: Y.Y. and L.W. designed the experiments and wrote the manuscript; G.L. assisted in performing some tests; R.L. helped to revise the manuscript. All authors have read and agreed to the published version of the manuscript.

Funding: This work is supported by National Natural Science Foundation of China (project Nos. 51677015 and 51437001).

Acknowledgments: We thank Jiaqi Jia and Lilu Qin for technical assistance.

Conflicts of Interest: The authors declare no conflict of interest.

\section{References}

1. Jung, S.K.; Shin, S.; Myong, R.; Cho, T.H. An efficient CFD-based method for aircraft icing simulation using a reduced order model. J. Mech. Sci. Technol. 2011, 25, 703-711. [CrossRef]

2. Ryerson, C.C. Ice protection of offshore platforms. Cold Reg. Sci. Technol. 2011, 65, 97-110. [CrossRef]

3. Kraj, A.G.; Bibeau, E.L. Phases of icing on wind turbine blades characterized by ice accumulation. Renew. Energy 2010, 35, 966-972. [CrossRef]

4. He, Z.; Vågenes, E.T.; Delabahan, C.; He, J.; Zhang, Z. Room temperature characteristics of polymer-based low ice adhesion surfaces. Sci. Rep. 2017, 7, 7. [CrossRef]

5. Dursun, T.; Soutis, C. Recent developments in advanced aircraft aluminium alloys. Mater. Des. 2014, 56, 862-871. [CrossRef] 
6. Singh, S.; Guo, E.; Xie, H.; Chawla, N. Mechanical properties of intermetallic inclusions in Al 7075 alloys by micropillar compression. Intermet 2015, 62, 69-75. [CrossRef]

7. Plummer, D.M.; Göke, S.; Rauber, R.M.; Di Girolamo, L. Discrimination of mixed-versus ice-phase clouds using dual-polarization radar with application to detection of aircraft icing regions*. J. Appl. Meteorol. Clim. 2010, 49, 920-936. [CrossRef]

8. Cancilla, D.A.; Holtkamp, A.; Matassa, L.; Fang, X.C. Isolation and characterization of microtox(R)-active components from aircraft de-icing/anti-icing fluids. Environ. Toxicol. Chem. 1997, 16, 430-434. [CrossRef]

9. Wang, N.; Xiong, D.; Deng, Y.; Shi, Y.; Wang, K. Mechanically robust superhydrophobic steel surface with anti-icing, UV-durability, and corrosion resistance properties. ACS Appl. Mater. Interfaces 2015, 7, 6260-6272. [CrossRef]

10. Xing, W.; Li, Z.; Yang, H.; Li, X.; Wang, X.; Li, N. Anti-icing aluminum alloy surface with multi-level micro-nano textures constructed by picosecond laser. Mater. Des. 2019, 183, 108156. [CrossRef]

11. Kulinich, S.A.; Farhadi, S.; Nose, K.; Du, X.W. Superhydrophobic surfaces: Are they really ice-repellent? Langmuir 2011, 27, 25-29. [CrossRef] [PubMed]

12. Varanasi, K.K.; Deng, T.; Smith, J.D.; Hsu, M.; Bhate, N. Frost formation and ice adhesion on superhydrophobic surfaces. Appl. Phys. Lett. 2010, 97, 234102. [CrossRef]

13. Cui, W.; Jiang, Y.; Mielonen, K.; Pakkanen, T.A. The verification of icephobic performance on biomimetic superhydrophobic surfaces and the effect of wettability and surface energy. Appl. Surf. Sci. 2019, 466, 503-514. [CrossRef]

14. Wong, T.-S.; Kang, S.H.; Tang, S.K.Y.; Smythe, E.J.; Hatton, B.D.; Grinthal, A.; Aizenberg, J. Bioinspired self-repairing slippery surfaces with pressure-stable omniphobicity. Nat. Cell Biol. 2011, 477, 443-447. [CrossRef]

15. Anand, S.; Paxson, A.T.; Dhiman, R.; Smith, J.D.; Varanasi, K.K. Enhanced condensation on lubricant-impregnated nanotextured surfaces. ACS Nano 2012, 6, 10122-10129. [CrossRef]

16. Kim, P.; Wong, T.-S.; Alvarenga, J.; Kreder, M.J.; Adorno-Martinez, W.E.; Aizenberg, J. Liquid-infused nanostructured surfaces with extreme anti-ice and anti-frost performance. ACS Nano 2012, 6, 6569-6577. [CrossRef] [PubMed]

17. Heale, F.L.; Parkin, I.P.; Carmalt, C.J. Slippery liquid infused porous $\mathrm{TiO}_{2} / \mathrm{SnO}_{2}$ nanocomposite thin films via aerosol assisted chemical vapor deposition with anti-icing and fog retardant properties. ACS Appl. Mater. Interfaces. 2019, 11, 41804-41812. [CrossRef]

18. Smith, J.D.; Dhiman, R.; Anand, S.; Reza-Garduno, E.; Cohen, R.E.; McKinley, G.H.; Varanasi, K.K. Droplet mobility on lubricant-impregnated surfaces. Soft Matter 2013, 9, 1772-1780. [CrossRef]

19. Vogel, N.; Belisle, R.A.; Hatton, B.; Wong, T.-S.; Aizenberg, J. Transparency and damage tolerance of patternable omniphobic lubricated surfaces based on inverse colloidal monolayers. Nat. Commun. 2013, 4, 2176. [CrossRef]

20. Chen, L.; Geissler, A.; Bonaccurso, E.; Zhang, K. Transparent slippery surfaces made with sustainable porous cellulose lauroyl ester films. ACS Appl. Mater. Interfaces 2014, 6, 6969-6976. [CrossRef]

21. Chen, Y.; Lu, K.J.; Chung, T.-S. An omniphobic slippery membrane with simultaneous anti-wetting and anti-scaling properties for robust membrane distillation. J. Membr. Sci. 2020, 595, 117572. [CrossRef]

22. Jiang, D.; Xia, X.; Hou, J.; Cai, G.; Zhang, X.; Dong, Z. A novel coating system with self-reparable slippery surface and active corrosion inhibition for reliable protection of Mg alloy. Chem. Eng. J. 2019, 373, $285-297$. [CrossRef]

23. Wang, G.; Liu, S.; Wei, S.; Liu, Y.; Lian, J.; Jiang, Q. Robust superhydrophobic surface on Al substrate with durability, corrosion resistance and ice-phobicity. Sci. Rep. 2016, 6, 20933. [CrossRef]

24. Shen, Y.; Wu, X.; Tao, J.; Zhu, C.; Lai, Y.; Chen, Z. Icephobic materials: Fundamentals, performance evaluation, and applications. Prog. Mater. Sci. 2019, 103, 509-557. [CrossRef]

25. Ling, E.J.Y.; Uong, V.; Renault-Crispo, J.-S.; Kietzig, A.-M.; Servio, P. Reducing ice adhesion on nonsmooth metallic surfaces: Wettability and topography effects. ACS Appl. Mater. Interfaces 2016, 8, 8789-8800. [CrossRef]

26. Momen, G.; Jafari, R.; Farzaneh, M. Ice repellency behaviour of superhydrophobic surfaces: Effects of atmospheric icing conditions and surface roughness. Appl. Surf. Sci. 2015, 349, 211-218. [CrossRef] 
27. Wilson, P.W.; Lu, W.; Xu, H.; Kim, P.; Kreder, M.J.; Alvarenga, J.; Aizenberg, J. Inhibition of ice nucleation by slippery liquid-infused porous surfaces (SLIPS). Phys. Chem. Chem. Phys. 2013, 15, 581-585. [CrossRef]

28. Boinovich, L.B.; Emelyanenko, A.M.; Korolev, V.V.; Pashinin, A.S. Effect of wettability on sessile drop freezing: When superhydrophobicity stimulates an extreme freezing delay. Langmuir 2014, 30, 1659-1668. [CrossRef]

Publisher's Note: MDPI stays neutral with regard to jurisdictional claims in published maps and institutional affiliations.

(C) 2020 by the authors. Licensee MDPI, Basel, Switzerland. This article is an open access article distributed under the terms and conditions of the Creative Commons Attribution (CC BY) license (http://creativecommons.org/licenses/by/4.0/). 